\title{
Estimativas de propriedades energéticas de pellets torrificados por meio de parâmetros colorimétricos
}

\author{
Mateus Alves de Magalhães*, Carlos Miguel Simões da Silva, Angélica de Cássia Oliveira Carneiro, \\ Benedito Rocha Vital, Vinícius Lima Teixeira, Lucas de Freitas Fialho, Clarissa Gusmão Figueiró
}

Departamento de Engenharia Florestal, Universidade Federal de Viçosa, Viçosa, MG, Brasil.

\begin{abstract}
RESUMO Parâmetros colorimétricos podem ser uma importante ferramenta para predizer a qualidade de produtos torrificados e auxiliar no controle da torrefação. Considerando a importância do controle do processo de torrefação para a qualidade do produto torrificado, o presente trabalho teve por objetivo correlacionar e ajustar modelos entre parâmetros colorimétricos e propriedades energéticas de pellets de pinus torrificados em um reator tipo rosca sem fim. Foram produzidos pellets e logo em seguida submetidos à torrefação nas temperaturas de 210,250 e $290{ }^{\circ} \mathrm{C}$ e nos tempos de residência de 10,20 e 30 minutos. Foram mensurados os parâmetros colorimétricos $L$ (claridade), $a$ (coordenada vermelho-verde) e $b$ (coordenada azul-amarelo), determinada a umidade de equilíbrio higroscópico, densidade a granel, poder calorífico útil e estimada a densidade energética. Foi avaliada a correlação entre os parâmetros colorimétricos e as propriedades dos pellets, e quando significativa foram ajustados modelos lineares ou não lineares para estimar tais propriedades em função dos parâmetros colorimétricos. O uso dos parâmetros $L$ e $b$ permitiu estimar de forma satisfatória as propriedades energéticas dos pellets de pinus torrificados, sendo uma técnica promissora para aplicação no controle da torrefação em tempo real, o que permite o aumento da qualidade e homogeneidade do produto final.

Palavras-chave: torrefação; sistema CIELab; peletização.
\end{abstract}

\section{Estimates of energy properties of torrefied pellets by colorimetric parameters}

\begin{abstract}
Colorimetric parameters can be an important tool to predict the quality of torrefied products and assist in the control of torrefaction. Considering the importance of control, the torrefaction process for quality of the torrefied product, the present work had the objective of correlating and adjusting models between colorimetric parameters and energy properties of pine pellets torrefied in a screw type reactor. Pellets were produced and submitted to torrefaction at temperatures of 210,250 and $290{ }^{\circ} \mathrm{C}$ and at residence times of 10, 20 and 30 minutes. Were measured the colorimetric parameters L (lightness), a (redgreen coordinate) and b (blue-yellow coordinate), determined the hygroscopic equilibrium moisture, bulk density, useful calorific value and estimated energy density. Was evaluated the correlation between the colorimetric parameters and the properties of pellets and, when significant, linear or nonlinear models were adjusted to estimate the properties as a function of the colorimetric parameters. The use of parameters $\mathrm{L}$ and $\mathrm{b}$ allowed a satisfactory estimation of energetic properties of the pine pellets torrefied, being a promising technique for application in torrefaction control in real time, allows the increase of quality and homogeneity of the final product.
\end{abstract}

Keywords: torrefaction; CIELab system; pelletization.

\section{Introdução}

Os pellets obtidos a partir da compactação da biomassa

vegetal são empregados na geração de energia térmica para o aquecimento de residências ou para utilização em processos industriais, principalmente em países da América do Norte e Europa. A peletização torna a biomassa um combustível mais homogêneo, reduz o seu volume e aumenta a densidade 
energética, otimizando seu armazenamento e transporte (WARAJANONT; SOPONPONGPIPAT, 2013; CHEN et al., 2015; WHITTAKER; SHIELD, 2017).

Apesar do incremento na qualidade energética, os pellets mantêm algumas das características da biomassa que os originou, como baixo poder calorífico em relação aos combustíveis não renováveis e a alta higroscopicidade, propriedades não desejáveis para a geração de energia térmica (LAM et al., 2012b). Uma forma de amenizar esses problemas é realizar a torrefação em temperaturas entre 200 e $300^{\circ} \mathrm{C}$ e em ambiente com baixa concentração de oxigênio, a qual promove a degradação de compostos menos energéticos e mais hidrofílicos contidos na biomassa, tendo como principal efeito o aumento da densidade energética (CHEW; DOSHI, 2011; VAN DER STELT et al., 2011; SHANG et al., 2012; NHUCHHEN et al., 2014).

Os pellets torrificados podem ser obtidos através de duas rotas, a primeira consiste em torrificar as partículas e produzir pellets e a segunda produzir pellets e em seguida submetê-los à torrefação (GHIASI et al., 2014; PENG et al., 2015). Na torrefação pós-peletização, os pellets devem ter alta resistência mecânica para que suportem o processo sem se desintegrar e gerar finos, considerando que os equipamentos mantêm a biomassa em constante movimentação. Essa rota envolve menor custo do processo de produção e dispensa o condicionamento com vapor para facilitar a peletização (GHIASI et al., 2014).

No processo de produção, o controle do tempo e temperatura de torrefação é extremamente importante para obtenção de pellets torrificados de alta qualidade. A avaliação de propriedades convencionais do material torrificado como a umidade de equilíbrio higroscópico, densidade a granel e poder calorífico, pode predizer o seu potencial para o uso energético e ajudar na tomada de decisão para intervenções pontuais na torrefação. No entanto, a determinação contínua dessas propriedades durante a produção é inviável devido ao tempo demandado e ao custo das análises.

Variações causadas pela torrefação nas propriedades energéticas dos pellets podem ter correlação com alterações no seu padrão de cor. Segundo Zanuncio et al. (2014) o primeiro efeito da torrefação é o escurecimento, que se torna mais gradativo com o aumento do tempo ou temperatura. A avaliação de parâmetros colorimétricos dos pellets torrificados pode ser feita repetidamente durante a torrefação, tendo como principal vantagem a sua rapidez.

Considerando a possibilidade de melhoria no controle da torrefação, redução de custos com análises de laboratório e a insuficiência de dados ou literatura sobre a estimação de propriedades de pellets com base em parâmetros de cor para auxílio no controle da torrefação, o objetivo deste trabalho foi avaliar a correlação e ajustar modelos entre parâmetros colorimétricos e propriedades energéticas de pellets de pinus torrificados em um reator tipo rosca sem fim.

\section{Material e Métodos}

\section{Produção e torrefação dos pellets}

A madeira de Pinus sp. em toras foi previamente transformada em partículas utilizando um moinho martelo. As partículas foram classificadas em peneiras sobrepostas, recolhendo-se a fração que passou pela peneira de $3 \mathrm{~mm}$ e ficou retida na de $0,5 \mathrm{~mm}$. Foram secas em estufa de circulação forçada a $60{ }^{\circ} \mathrm{C}$ até atingirem, aproximadamente, $16 \%$ de umidade. Os pellets foram produzidos em uma prensa peletizadora laboratorial da marca Amandus Kahl, modelo 14-175, a uma temperatura média de $106^{\circ} \mathrm{C}$.

Para a torrefação, inicialmente, os pellets foram secos em estufa a $103 \pm 2{ }^{\circ} \mathrm{C}$ até $0 \%$ de umidade. Foram utilizados aproximadamente $5 \mathrm{~kg}$ para cada tratamento térmico. Foram utilizadas três temperaturas $\left(210,250\right.$ e $\left.290^{\circ} \mathrm{C}\right)$ e três tempos 


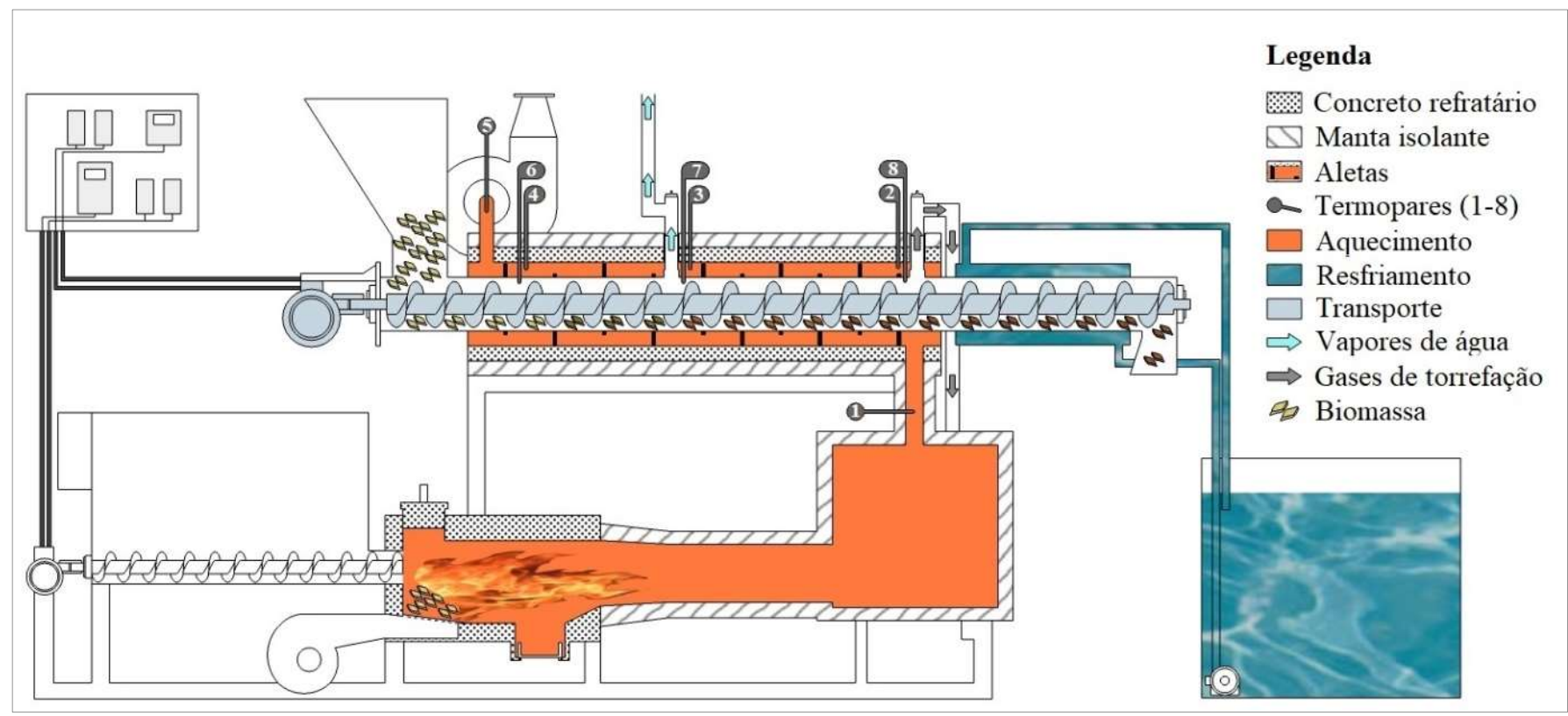

Figura 1. Esquema do sistema de torrefação de biomassa. Patente requerida - BR 102016.0104840.

Figure 1. Scheme of the biomass torrefaction system. Required Patent - BR 1020160104840.

de residência (10, 20 e 30 minutos). O reator utilizado é do tipo rosca sem fim (Figura 1), foi desenvolvido no Laboratório de Painéis e Energia da Madeira na Universidade Federal de Viçosa, MG.

\section{Propriedades dos pellets}

Para a determinação da umidade de equilíbrio higroscópico, amostras foram colocadas em uma câmara climática a $20{ }^{\circ} \mathrm{C}$ e $65 \%$ de umidade relativa até atingirem massa constante. A determinação do teor de umidade, em base seca, foi feita de acordo com a norma EN 14774-2 (DIN, 2009).

A densidade a granel foi obtida de acordo com a norma EN 15103 (DIN, 2010b), em amostras condicionadas a 65\% de umidade relativa e $20^{\circ} \mathrm{C}$ de temperatura.

O poder calorífico útil foi estimado a partir do poder calorífico superior utilizando a Equação 1, conforme o Anexo E da norma EN 14918 (DIN, 2010a). O poder calorífico superior foi determinado de acordo com a norma EN 14918 (DIN, 2010a) e os teores de hidrogênio, oxigênio e nitrogênio foram obtidos conforme a norma EN 15104 (DIN, 2011).
PCU (pressão constante) $=\left(\mathrm{PCS}-212,2^{\star} \mathrm{H}-0,8^{\star}(\mathrm{O}+\mathrm{N})\right) *(1-0,01$

$\left.{ }^{\star} \mathrm{M}\right)-\left(24,43{ }^{\star} \mathrm{M}\right)$

Sendo: PCU (pressão constante): poder calorífico útil em pressão constante, em J/g; PCS: poder calorífico superior, em J/g; $\mathrm{H}$, $\mathrm{O}, \mathrm{N}$ : hidrogênio, oxigênio e nitrogênio, respectivamente, em porcentagem (\%); M: umidade de equilíbrio higroscópico, base úmida, em porcentagem (\%); Constantes: A energia de vaporização (pressão constante) para a água a $25^{\circ} \mathrm{C}$ é de 44,01 $\mathrm{kJ} / \mathrm{mol}$. Isto corresponde a $218,3 \mathrm{~J} / \mathrm{g}$ para $1 \%$ de hidrogênio $(\mathrm{m} / \mathrm{m})$ ou $24,43 \mathrm{~J} / \mathrm{g}$ para $1 \%$ de umidade $(\mathrm{m} / \mathrm{m})$ na amostra.

A densidade energética foi obtida por meio do produto do poder calorífico útil pela densidade a granel.

\section{Análise colorimétrica}

A análise colorimétrica foi realizada pela mensuração da claridade (L), a coordenada vermelho-verde (a) e a coordenada azul-amarelo (b), também denominado como sistema de cor CIELab, definido pela Comissão Internacional sobre Iluminação (CIE) (Figura 2). Para cada tratamento foram realizadas 5 medições, em amostras de pellets 
homogeneizadas e moídas, utilizando um espectrofotômetro Konica Minolta CM-2500D. A umidade das amostras estava próxima a $0 \%$, devido à secagem prévia ao tratamento térmico. As medições de cor nos pellets torrificados foram realizadas em amostras coletadas durante a torrefação.

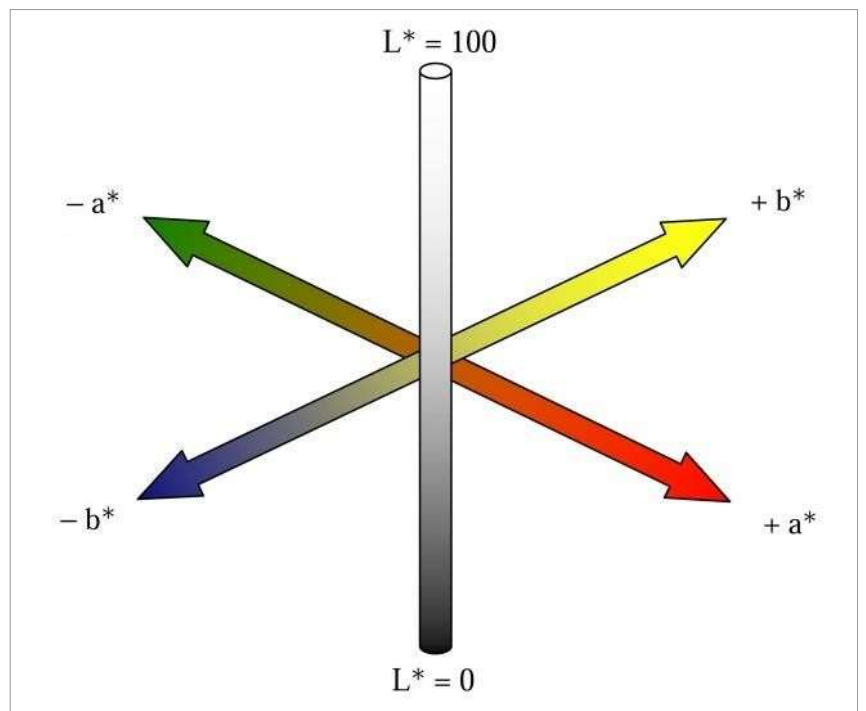

Figura 2. Esquema tridimensional de cor CIELab. Adaptado de Liew et al. (2008).

Figure 2. CIELab three-dimensional color scheme. Adapted from Liew et al. (2008).

\section{Análise de dados}

O experimento foi conduzido de acordo com um delineamento inteiramente casualizado com 10 tratamentos e três repetições, totalizando 30 unidades amostrais. A normalidade dos dados foi verificada pelo teste de Lilliefors e homogeneidade de variância por Hartley, Cochran e Bartlett, sendo estas pressuposições atendidas.

Foi realizada análise de correlação de Pearson entre os parâmetros colorimétricos e as propriedades energéticas dos pellets, e testada sua significância a 5\% pelo teste-t de Student.

Foram ajustados modelos lineares e não lineares para estimar as propriedades energéticas dos pellets utilizando os parâmetros colorimétricos. Os modelos que mais se adequaram a dispersão dos dados foram utilizados na estimação. Para verificar a significância dos parâmetros da equação ajustada, foi realizado o teste t de Student. O critério utilizado para determinar a qualidade do ajuste do modelo aos dados experimentais foi o erro padrão residual $\left(s_{y . x}\right)$ e coeficiente de determinação $\left(\mathrm{R}^{2}\right)$. As análises foram realizadas utilizando o software R (R CORE TEAM, 2017).

\section{Resultados e Discussão}

Os valores da claridade $(L)$ reduziram com o aumento do tempo ou temperatura de torrefação, indicando que houve um escurecimento dos pellets. Os valores do matiz vermelhoverde $(a)$ tenderam a aumentar até tempos ou temperaturas intermediárias e reduzir com a intensificação do tratamento térmico. Os valores do matiz azul-amarelo $(b)$ diminuíram, principalmente, em maiores tempos e temperaturas de torrefação, Tabela 1. O mesmo padrão de variação das coordenadas $L$, $a$ e $b$ foi observado por Moura e Brito (2011) ao estudarem o efeito do tratamento térmico sobre as propriedades colorimétricas da madeira de pinus.

Dentre as alterações na cor da madeira devido ao tratamento térmico, a principal delas é o escurecimento (ZANUNCIO et al., 2014). O escurecimento é consequência da degradação e oxidação de componentes estruturais menos estáveis termicamente como as hemiceluloses e, em menor grau, a celulose. Ademais, os extrativos presentes na madeira podem sofrer modificações durante o tratamento térmico. Essas alterações químicas levam a formação de produtos que absorvem a luz visível, tornando a madeira escura (CONTE et al., 2014; GARCIA et al., 2014; ZANUNCIO et al., 2014).

Esteves et al. (2008), ao estudar mudanças na cor da madeira de pinus devido ao tratamento térmico, encontraram forte correlação entre a redução da claridade com o decréscimo no teor de hemiceluloses, já para a lignina e extrativos obtiveram piores correlações. Pertuzzatti et al. (2016) também observaram redução da claridade ao estudar o efeito do tratamento térmico sobre a madeira de pinus. 
Tabela 1. Valores médios dos parâmetros colorimétricos em função dos tratamentos

Table 1. Mean values of colorimetric parameters as a function of treatments

\begin{tabular}{llll}
\hline Tratamentos & \multicolumn{1}{c}{$\boldsymbol{b}$} & $\boldsymbol{a}$ & $24,5(0,59)$ \\
\hline $1-$ Controle & $70,0(0,67)$ & $8,0(0,44)$ & $24,8(0,19)$ \\
\hline $2-210^{\circ} \mathrm{C} / 10 \mathrm{~min}$ & $68,1(0,79)$ & $8,9(0,20)$ & $24,3(0,44)$ \\
\hline $3-210^{\circ} \mathrm{C} / 20 \mathrm{~min}$ & $64,2(0,80)$ & $9,5(0,38)$ & $24,9(0,37)$ \\
\hline $4-210^{\circ} \mathrm{C} / 30 \mathrm{~min}$ & $64,4(0,34)$ & $9,8(0,36)$ & $24,9(0,14)$ \\
\hline $5-250^{\circ} \mathrm{C} / 10 \mathrm{~min}$ & $62,9(0,22)$ & $10,0(0,23)$ & $21,1(0,22)$ \\
\hline $6-250^{\circ} \mathrm{C} / 20 \mathrm{~min}$ & $44,2(0,49)$ & $11,6(0,11)$ & $15,7(0,20)$ \\
\hline $7-250^{\circ} \mathrm{C} / 30 \mathrm{~min}$ & $32,5(0,46)$ & $10,8(0,35)$ & $23,9(0,32)$ \\
\hline $8-290^{\circ} \mathrm{C} / 10 \mathrm{~min}$ & $61,6(0,24)$ & $9,7(0,18)$ & $17,9(0,16)$ \\
\hline $9-290^{\circ} \mathrm{C} / 20 \mathrm{~min}$ & $36,5(0,29)$ & $11,0(0,06)$ & $5,1(0,17)$ \\
\hline $10-290^{\circ} \mathrm{C} / 30 \mathrm{~min}$ & $21,6(0,47)$ & $4,8(0,14)$ & \\
\hline
\end{tabular}

Valores entre parênteses correspondem ao desvio padrão.

Moura e Brito (2011) observaram correlação positiva entre a redução da claridade e do teor de holocelulose (hemiceluloses e celulose) e correlação inversa com o teor de lignina da madeira, no entanto esses autores encontraram correlações inferiores às obtidas por Esteves et al. (2008) para ambos os componentes estruturais.

O aumento inicial de $a$ (coordenada vermelho-verde) se deve a formação de substâncias fenólicas (MOURA; BRITO, 2011), as quais são degradadas ou volatilizadas com o aumento do tempo ou temperatura de torrefação, refletindo na redução desse parâmetro colorimétrico (ESTEVES; PEREIRA, 2009). Alguns autores também atribuem esses resultados à formação de produtos de condensação e oxidação da lignina, os chamados quinonas (GONZÁLEZPEÑA; HALE, 2009).

Segundo Moura e Brito (2011) a coloração amarela da madeira é decorrente da presença de grupos cromóforos na lignina e extrativos, também devido a complexos organometálicos dos extrativos. A redução de $b$ (coordenada azul-amarelo) como a intensificação do tratamento térmico ocorre devido á degradação e oxidação desses componentes estruturais, diminuindo os tons de amarelo predominantes na madeira in natura.

Observa-se, na Tabela 2, que a umidade de equilíbrio higroscópico obteve correlação significativa e positiva apenas com os parâmetros $L$ e $b, 0,96$ e 0,90 respectivamente, indicando a redução da umidade juntamente com os valores desses parâmetros. Todos os três parâmetros tiveram correlação significativa e positiva com a densidade a granel, sendo 0,78 para o $L, 0,67$ para o $a$ e 0,92 para o $b$. O poder calorífico útil e a densidade energética apresentaram correlação significativa apenas com os parâmetros $L$ e $b$, sendo negativa para ambos.

O parâmetro $a$, apesar de não apresentar grande variabilidade dos dados (Tabela 1), obteve as piores correlações com as propriedades energéticas dos pellets (Tabela 2), sendo explicado pelo seu padrão de variação, no qual seus valores aumentaram até certas temperaturas e tempos intermediários e reduziram com a intensificação do tratamento térmico. Já as propriedades dos pellets tiveram tendência de aumento ou redução, dessa forma não foi estabelecida uma estreita relação entre elas e a variação do parâmetro $a$. 
Tabela 2. Correlação entre os parâmetros colorimétricos e as propriedades dos pellets

Table 2. Correlation between colorimetric parameters and properties of the pellets

\begin{tabular}{lcccc}
\hline \multirow{2}{*}{$\begin{array}{l}\text { Parâmetros } \\
\text { Colorimétricos }\end{array}$} & Propriedades Energéticas \\
\cline { 2 - 5 } & UEH & DG & PCU & DE \\
\hline$L$ & $0,96^{\star}$ & $0,78^{\star}$ & $-0,96^{\star}$ & $-0,92^{\star}$ \\
\hline$a$ & 0,20 & $0,67^{\star}$ & $-0,41^{\star}$ & 0,03 \\
\hline$b$ & $0,90^{\star}$ & $0,92^{\star}$ & $-0,98^{\star}$ & $-0,78^{\star}$ \\
\hline
\end{tabular}

* Correlação significativa a 5\% de significância.

$\mathrm{UEH}=$ umidade de equilíbrio higroscópico, $\mathrm{DG}=$ densidade a granel, $\mathrm{PCU}=$ poder calorífico útil, $\mathrm{DE}=$ densidade energética.

O coeficiente de correlação de Pearson mede o grau de associação entre duas variáveis (CALLEGARI-JACQUES, 2009). Uma boa correlação pode indicar um possível ajuste de um modelo para estimar variáveis dependentes (propriedades energéticas) a partir de uma ou mais variáveis independentes (parâmetros colorimétricos). Deste modo, os parâmetros colorimétricos $L$ e $b$, por apresentarem um alto grau de associação com as propriedades energéticas dos pellets, em comparação com o parâmetro $a$, foram utilizados para o ajuste de equações.

Na Tabela 3 estão apresentados os ajustes referentes aos modelos que mais se adequaram a dispersão dos dados. De forma geral, observa-se que tanto para o parâmetro $L$, quanto para o $b$, as equações apresentaram bons ajustes para todas as propriedades energéticas dos pellets.

Tabela 3. Modelos, estimativas e significância dos parâmetros estatísticos e medidas de precisão das equações ajustadas Table 3. Models, estimates and significance of the statistical parameters and precision measures of adjusted equations

\begin{tabular}{|c|c|c|c|c|c|c|c|}
\hline $\begin{array}{c}\text { Parâmetros } \\
\text { Colorimétricos }\end{array}$ & $\begin{array}{l}\text { Propriedades } \\
\text { Energéticas }\end{array}$ & Modelo & $\begin{array}{c}\text { Estimativa dos } \\
\text { Parâmetros } \\
\text { Estatísticos }\end{array}$ & p-valor & Sy,x & $\mathbf{R}^{2}$ & $\mathbf{R}_{(\text {ajustado) }}^{2}$ \\
\hline \multirow{4}{*}{$L$} & $\mathrm{UEH}$ & $\mathrm{UEH}=\beta_{0}+\beta_{1} L+\varepsilon$ & $\begin{array}{l}\beta_{0}=3,77 \\
\beta_{1}=0,09\end{array}$ & $\begin{array}{l}<0,01 \\
<0,01\end{array}$ & 0,48 & 91,96 & 91,67 \\
\hline & DG & $\mathrm{DG}=\beta_{0} /\left(1+\beta_{1} \mathrm{e}^{(\beta 2 L)}\right)$ & $\begin{array}{l}\beta_{0}=626,67 \\
\beta_{1}=3,82 \\
\beta_{2}=0,16\end{array}$ & $\begin{array}{l}<0,01 \\
<0,01 \\
<0,01\end{array}$ & 6,75 & 92,87 & 92,49 \\
\hline & PCU & $\mathrm{PCU}=\beta_{0} /\left(1+\beta_{1} \mathrm{e}^{(\beta 2 L)}\right)$ & $\begin{array}{l}\beta_{0}=16,20 \\
\beta_{1}=-0,46 \\
\beta_{2}=0,04\end{array}$ & $\begin{array}{l}<0,01 \\
<0,01 \\
<0,01\end{array}$ & 0,15 & 97,79 & 97,67 \\
\hline & $\mathrm{DE}$ & $\mathrm{DE}=\beta_{0} /\left(1+\left(L / \beta_{1}\right)^{(\beta 2)}\right)$ & $\begin{array}{l}\beta_{0}=11,52 \\
\beta_{1}=181,14 \\
\beta_{2}=2,41\end{array}$ & $\begin{array}{l}<0,01 \\
<0,01 \\
<0,01\end{array}$ & 0,12 & 84,58 & 83,74 \\
\hline \multirow{4}{*}{$b$} & $\mathrm{UEH}$ & $\mathrm{UEH}=\beta_{0} /\left(1+\beta_{1} \mathrm{e}^{(\beta 2 b)}\right)$ & $\begin{array}{l}\beta_{0}=-0,0027 \\
\beta_{1}=-1,00 \\
\beta_{2}=0,000012\end{array}$ & $\begin{array}{l}<0,01 \\
<0,01 \\
<0,01\end{array}$ & 0,56 & 81,59 & 80,60 \\
\hline & DG & $\mathrm{DG}=\beta_{0} /\left(1+\beta_{1} \mathrm{e}^{(\beta 2 b)}\right)$ & $\begin{array}{l}\beta_{0}=632,42 \\
\beta_{1}=0,29 \\
\beta_{2}=0,14\end{array}$ & $\begin{array}{l}<0,01 \\
<0,01 \\
<0,01\end{array}$ & 4,48 & 94,58 & 94,28 \\
\hline & PCU & $\mathrm{PCU}=\beta_{0} /\left(1+\left(b / \beta_{1}\right)^{(\beta 2)}\right)$ & $\begin{array}{l}\beta_{0}=20,79 \\
\beta_{1}=58,80 \\
\beta_{2}=1,70\end{array}$ & $\begin{array}{l}<0,01 \\
<0,01 \\
<0,01 \\
\end{array}$ & 0,19 & 96,3 & 96,10 \\
\hline & $\mathrm{DE}$ & $\mathrm{DE}=\beta_{0} /\left(1+\left(b / \beta_{1}\right)^{(\beta 2)}\right)$ & $\begin{array}{l}\beta_{0}=11,44 \\
\beta_{1}=38,43 \\
\beta_{2}=5,70\end{array}$ & $\begin{array}{l}<0,01 \\
<0,01 \\
<0,01\end{array}$ & 0,13 & 83,93 & 83,06 \\
\hline
\end{tabular}

UEH = umidade de equilíbrio higroscópico (\%), DG = densidade a granel $\left(\mathrm{kg} / \mathrm{m}^{3}\right), \mathrm{PCU}=$ poder calorífico útil $(\mathrm{MJ} / \mathrm{kg}), \mathrm{DE}=$ densidade energética $\left(\mathrm{GJ} / \mathrm{m}^{3}\right)$. 
As equações ajustadas para estimar a umidade de equilíbrio higroscópico, o poder calorífico útil e a densidade energética, utilizando como variável independente o parâmetro colorimétrico $L$, apresentaram os melhores ajustes, em comparação com aquelas que utilizaram o parâmetro $b$ como variável independente. Tais equações apresentaram os maiores coeficientes de determinação $\left(R^{2}\right)$ e os menores erros padrão da estimativa (Sy,x).

No entanto, no que diz respeito às equações obtidas para a estimação da densidade a granel, o emprego do parâmetro $b$ como variável independente foi mais eficiente em relação ao parâmetro L, apresentando maior coeficiente de determinação e menor erro padrão da estimativa.

Sawai et al. (2017) correlacionaram o rendimento em massa da torrefação com os parâmetros colorimétricos, segundo os autores foi possível estimar o rendimento com um erro de $\pm 10 \%$, no entanto utilizaram apenas os parâmetros $L$ e a. Amorim et al. (2013) também utilizaram os parâmetros colorimétricos para estimação de propriedades da madeira e para diferenciar a madeira de eucalipto e pinus, segundo os autores os resultados encontrados foram satisfatórios. Lam et al. (2012a) correlacionaram parâmetros colorimétricos com propriedades químicas e físicas da biomassa tratada termicamente por meio de regressão linear múltipla, os autores encontraram coeficientes de determinação superiores a 96\% e consideraram essa técnica eficaz para rápida obtenção de propriedades da biomassa.

As dispersões dos valores observados e estimados para as propriedades energéticas dos pellets, apresentadas nas Figuras 3 e 4, corroboram com os resultados apresentados na Tabela 3.
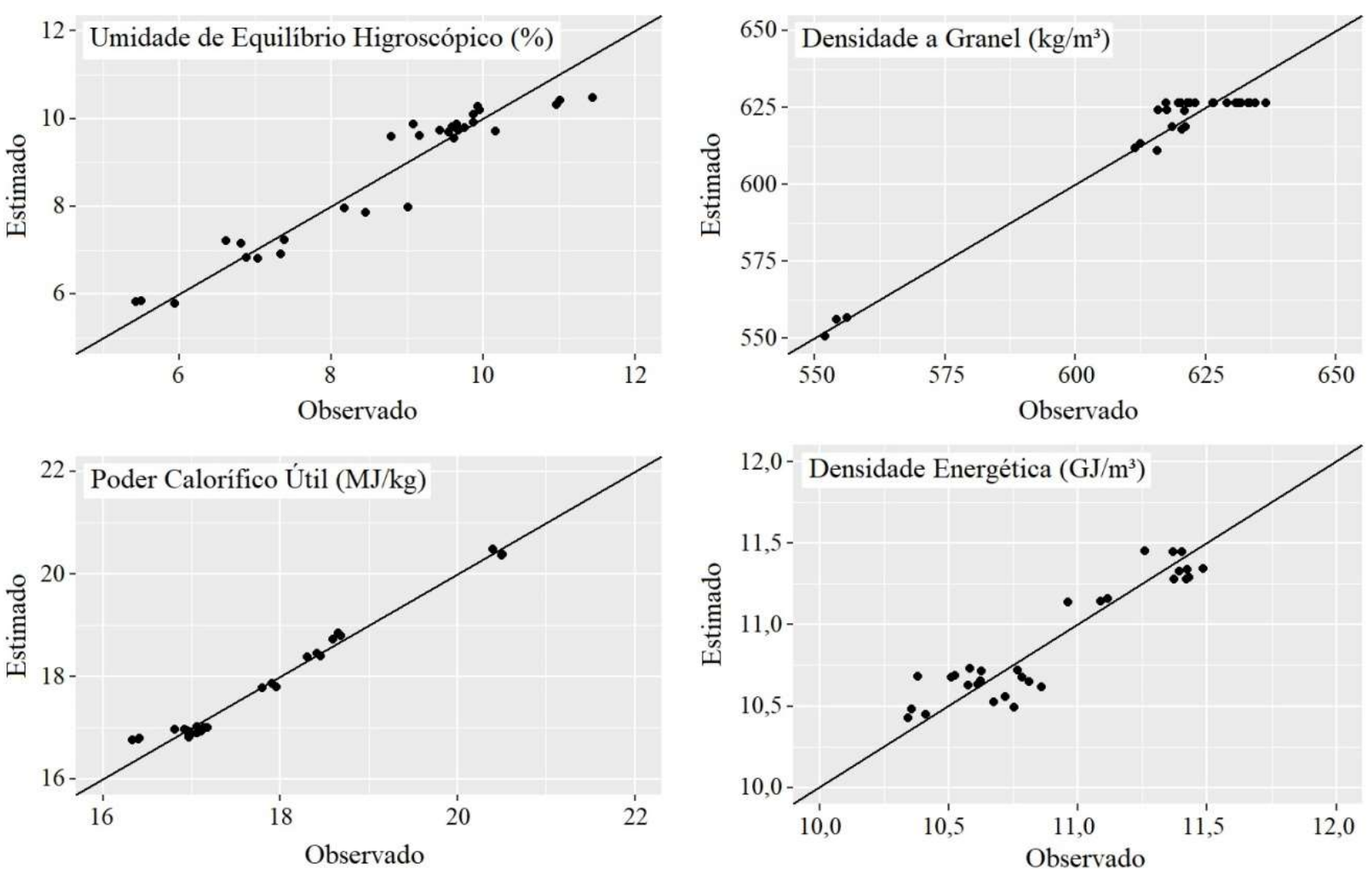

Figura 3. Dispersão dos valores observados e estimados para as equações ajustadas utilizando o parâmetro colorimétrico $L$.

Figure 3. Dispersion of observed and estimated values for adjusted equations using the colorimetric parameter $L$. 

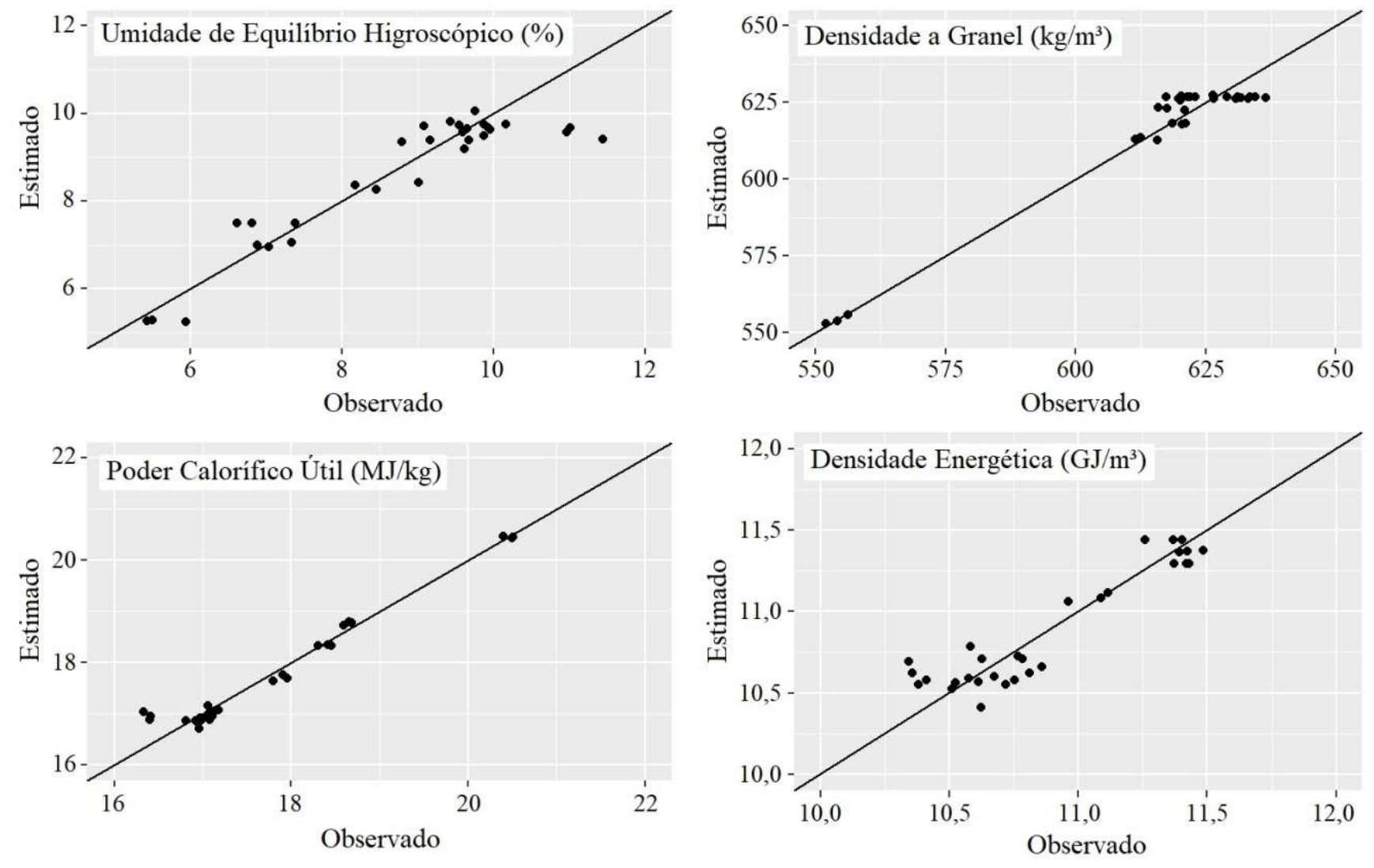

Figura 4. Dispersão dos valores observados e estimados para as equações ajustadas utilizando o parâmetro colorimétrico $b$.

Figure 4. Dispersion of observed and estimated values for adjusted equations using the colorimetric parameter $b$.

As equações permitem estimar de forma satisfatória as propriedades energéticas dos pellets de madeira, sendo possível utilizar tanto o parâmetro colorimétrico $L$ quanto o $b$.

Considerando a praticidade da determinação das variáveis colorimétricas durante a torrefação de pellets, essa ferramenta pode representar um ganho no controle de qualidade do produto torrificado e a redução no número de análises laboratoriais. Em um processo industrial, medições rápidas e contínuas de caraterísticas do produto contribuem para uma produção eficiente e financeiramente mais viável (LAM et al., 2012a).

Ressalta-se que cada tipo de biomassa, quando torrificada, apresenta um comportamento colorimétrico distinto, sendo necessário o ajuste de modelos para cada situação.

\section{Conclusões}

A utilização dos parâmetros colorimétricos $L$ e $b$ permitiu estimar de forma satisfatória propriedades energéticas dos pellets de pinus torrificados. O parâmetro $a$, por apresentar menor correlação com as propriedades dos pellets, não foi empregado no ajuste dos modelos.

Para as condições consideradas neste trabalho, o modelo mais indicado para a estimação da umidade de equilíbrio higroscópico foi o $\beta_{0}+\beta_{1} L+\varepsilon$, para a densidade a granel o $\beta_{0} /\left(1+\beta_{1} \mathrm{e}^{(\beta 2 b)}\right)$, para o poder calorífico útil o $\beta_{0} /\left(1+\beta_{1} \mathrm{e}^{(\beta 2 L)}\right) \mathrm{e}$ para a densidade energética o $\beta_{0} /\left(1+\left(L / \beta_{1}\right)^{(\beta 2)}\right)$.

A estimação das propriedades energéticas dos pellets, por meio dos parâmetros colorimétricos, é uma técnica promissora para aplicação no controle da torrefação em tempo real, o que permite o aumento da qualidade e homogeneidade do produto final. Acrescenta-se ainda a 
menor necessidade de análises laboratoriais, com consequente redução de custos, para conhecimento das propriedades do produto torrificado.

\section{Referências}

AMORIM, P. G. R.; GONÇALEZ, J. C.; CAMARGOS, J. A. A. Propriedades da madeira de Pinus caribaea e Eucalyptus grandis estimadas por colorimetria. CERNE, v. 19, n. 3, p. 461-466, 2013.

CALLEGARI-JACQUES, S. M. Bioestatística: Princípios e aplicações. 1 Ed. ed. Porto Alegre, Rio Grande do Sul: Artmed Editora, 2009. 253 p.

CHEN, W.H.; PENG, J.; BI, X. T. A state-of-the-art review of biomass torrefaction, densification and applications. Renewable and Sustainable Energy Reviews, v. 44, p. 847 $866,2015$.

CHEW, J. J.; DOSHI, V. Recent advances in biomass pretreatment - Torrefaction fundamentals and technology. Renewable and Sustainable Energy Reviews, v. 15, n. 8, p. 4212-4222, 2011.

CONTE, B.; MISSIO, A. L.; PERTUZZATTI, A.; DE CADEMARTORI, P. H.; GATTO, D. A. Propriedades físicas e colorimétricas da madeira termorretificada de Pinus elliottii var. elliottii. Scientia Forestalis, v. 42, n. 104, p. 555-563, 2014.

DIN - DEUTSCHES INSTITUT FUR NORMUNG. EN 14774-2: Solid biofuels - Determination of moisture content - Oven dry method - Part 2: Total moisture Simplified method. Berlim: CEN: 9 p. 2009.

EN 14918: Determination of calorific value. Berlim: CEN: 63 p. 2010a.

EN 15103: Solid biofuels - Determination of bulk density. Berlim: CEN: 14 p. 2010 b.

EN 15104: Determination of total content of carbon, hydrogen and nitrogen - Instrumental methods. Berlim: CEN: 15 p. 2011.

ESTEVES, B.; PEREIRA, H. Wood modification by heat treatment: A review. BioResources, v. 4, n. 1, p. 370-404, 2009.
ESTEVES, B.; VELEZ MARQUES, A.; DOMINGOS, I.; PEREIRA, H. Heat-induced colour changes of pine (Pinus pinaster) and eucalypt (Eucalyptus globulus) wood. Wood Science and Technology, v. 42, n. 5, p. 369-384, 2008.

GARCIA, R. A.; LOPES, J. D. O.; SANTOS, W. A. Modificação da cor original da madeira de Eucalyptus grandis através de tratamentos termorretificadores. CERNE, v. 20, p. 449-457, 2014.

GHIASI, B.; KUMAR, L.; FURUBAYASHI, T.; LIM, C. J.; BI, X.; KIM, C. S.; SOKHANSANJ, S. Densified biocoal from woodchips: Is it better to do torrefaction before or after densification? Applied Energy, v. 134, p. 133-142, 2014.

GONZÁlEZ-PEÑA, M. M.; HALE, M. D. C. Colour in thermally modified wood of beech, Norway spruce and Scots pine. Part 1: Colour evolution and colour changes. Holzforschung, v. 63, n. 4, p. 385-393, 2009.

LAM, P. S.; SOKHANSANJ, S.; BI, X. T.; LIM, C. J. Colorimetry applied to steam-treated biomass and pellets made from western Douglas fir (Pseudotsuga menziesii L.). Transactions of the ASABE, v. 55, n. 2, p. 673-678, $2012 \mathrm{a}$.

LAM, P. S.; SOKHANSANJ, S.; BI, X. T.; LIM, C. J.; LARSSON, S. H. Drying characteristics and equilibrium moisture content of steam-treated Douglas fir (Pseudotsuga menziesii L.). Bioresource Technology, v. 116, p. 396-402, 2012b.

LIEW, O.; CHONG, P.; LI, B.; ASUNDI, A. Signature Optical Cues: Emerging Technologies for Monitoring Plant Health. Sensors, v. 8, n. 5, p. 3205-3239, 2008.

MOURA, L. F.; BRITO, J. O. Efeito da termorretificação sobre as propriedades colorimétricas das madeiras de Eucalyptus grandis e Pinus caribaea var. hondurensis. Scientia Forestalis, v. 39, n. 89, p. 069-076, 2011.

NHUCHHEN, D. R.; BASU, P.; ACHARYA, B. A Comprehensive Review on Biomass Torrefaction. International Journal of Renewable Energy \& Biofuels, v. 2014, p. 1-56, 2014.

PENG, J.; WANG, J.; BI, X. T.; LIM, C. J.; SOKHANSANJ, S.; PENG, H.; JIA, D. Effects of thermal treatment on energy density and hardness of torrefied wood pellets. Fuel Processing Technology, v. 129, p. 168-173, 2015.

PERTUZZATTI, A.; MISSIO, A. L.; CONTE, B.; SOUZA, S. C.; SANTINI, E. J.; HASELEIN, C. R. Propriedades físicas da 
madeira de Pinus elliottii var. elliottii termorretificada sob diferentes atmosferas. Ciência da Madeira, v. 7, n. 1, p. 7-15, 2016.

R CORE TEAM. R: A language and environment for statistical computing. Vienna, Austria: R Foundation for Statistical Computing, 2017.

SAWAI, T.; KATAYAMA, I.; IDA, T.; IMAMURA, H.; KAJIMOTO, T. Estimation of energy properties of torrefied Japanese cedar with colorimetric values. Mechanical Engineering Journal, v. 4, n. 1, p. 1-14, 2017.

SHANG, L.; NIELSEN, N. P. K.; DAHL, J.; STELTE, W.; AHRENFELDT, J.; HOLM, J. K.; THOMSEN, T.; HENRIKSEN, U. B. Quality effects caused by torrefaction of pellets made from Scots pine. Fuel Processing Technology, v. 101, p. 23-28, 2012.

VAN DER STELT, M. J. C.; GERHAUSER, H.; KIEL, J. H. A.; PTASINSKI, K. J. Biomass upgrading by torrefaction for the production of biofuels: A review. Biomass and Bioenergy, v. 35, n. 9, p. 3748-3762, 2011.

WARAJANONT, S.; SOPONPONGPIPAT, N. Effect of particle size and moisture content on cassava root pellet fuel's qualities follow the acceptance of pellet fuel standard. International Journal of Renewable and Sustainable Energy, v. 2, n. 2, p. 74-79, 2013.

WHITTAKER, C.; SHIELD, I. Factors affecting wood, energy grass and straw pellet durability - A review. Renewable and Sustainable Energy Reviews, v. 71, p. 1-11, 2017.

ZANUNCIO, A. J. V.; FARIAS, E. D. S.; SILVEIRA, T. A. D. Termorretificação e colorimetria da madeira de Eucalyptus grandis. Floresta e Ambiente, v. 21, p. 85-90, 2014. 